\title{
The social and physical consequences of weight stigma in obese adolescents - primary care view
}

\author{
Mira FLOREA ${ }^{1}$, Lucia LOTREAN ${ }^{1}$, Aida PUIA ${ }^{1}$, loana PARA ${ }^{2}$, \\ Anca Angela SIMIONESCU ${ }^{3,4}$, Ana Maria Alexandra STANESCU 5 \\ ${ }^{1}$ Community Medicine Department, "Iuliu Hatieganu" University of Medicine and Pharmacy, \\ Cluj-Napoca, Romania \\ ${ }^{2}$ Internal Medicine Department, "Iuliu Hatieganu" University of Medicine and Pharmacy, \\ Cluj-Napoca, Romania \\ ${ }^{3}$ Department of Obstetrics and Gynecology, \\ "Carol Davila" University of Medicine and Pharmacy, Bucharest, Romania \\ ${ }^{4}$ Department of Obstetrics and Gynecology, Filantropia Clinical Hospital, Bucharest, Romania \\ ${ }^{5}$ Department of Family Medicine, "Carol Davila" University of Medicine and Pharmacy, Bucharest, Romania
}

\begin{abstract}
Negative attitudes regarding obese adolescents are learned early in life. Weight stigmatizing experiences occur frequently in the context of personal relationships with peers, teachers, family members, and health professionals. Adolescents' weight stigma is insufficiently considered in the obesity's management, and this contributes to negative heal th outcomes and behaviors that act as obesogenic factors into adulthood. Primary care professionals provide opportunity for translating expert recommendations for heal thy behavior changes of obese adolescents, having facilities and staff to implement them in the community. However, comprehensive programs for controlling body weight and stigmatizing obese adolescents are not sufficiently addressed in primary care because they require psycho-educational skills development and dedicated time. In the framework of the curricular reform of the family medicine residency program a study design in the community served by the family physician trainer and carried out with the family medicine residents involvement was included. We describe an integrative community-based educational program dedicated to the social and physical health consequences of obese adolescents' weight stigma that should be implemented in primary care.

Conclusions. Psycho-educational skills development in the future family doctors training will lead to greater efficacy in addressing emotional needs of obese adolescents. Their increased involvement in counseling parents will help better cope with their children's eating disorders and weight-based victimization.
\end{abstract}

Keywords: obese adolescents, weight stigma, primary care

\section{INTRODUCTION}

Obesity and related comorbidities including weightbased stigmatization are today one of the major public health issues, but not sufficiently addressed, regardless of the age of the patient. The trend is particularly alarming in children. Words such as "epidemic" or "pandemic" childhood obesity underlie the fact that 
even in children, obesity is emerging as a world global problem [1,2]. Adolescent obesity has physical health and social consequences $[3,4]$, and is strongly linked with obesity during adulthood $[5,6]$. Negative attitudes regarding obese adolescents are learned early in life. Weight stigmatizing experiences occur frequently in the context of personal relationships with peers, teachers, family members, and health professionals. Adolescents' weight stigma is rarely considered in the longterm management of obesity, and this contributes to negative health outcomes and behaviors that act as an obesogenic factor into adulthood. Weight stigma includes attitudes, beliefs manifested as negative stereotypes, prejudice, ignoring and even rejection of obese person. The slim figure promoted by media has been accepted by the modern urban civilization, and overweight people began to be considered unattractive, less competent and sociable [7]. Although weight stigma is often tolerated in the community, considering that shame will motivate weight loss, sometimes, especially in adolescents it produces demotivation, leading to binge eating and disincentive for sports. Teasing and social rejection by peers are connected to psychological problems, and maladaptative eating behaviors such as strict dieting, fasting, self-induced vomiting, misuse of diet pills, laxatives [8]. Teachers have lower expectation from obese adolescent perceiving them to be lazy, having poor will, and lack of self-discipline. In addition, there is a personal experience of adolescents' shame, negative self-evaluation, or perceived discrimination by teachers that is part of weight self-stigma. Family members sometimes show embarrassment to the body appearance of their obese children and contribute to the limitation of social activities. Weight-based stigmatization is also common in healthcare settings [9], and has been observed among physicians, nurses, medical students, and dietitians [10]. The stigma of being overweight has been called debilitating because it cannot be hidden, and others see obesity as controllable [11] and should be carefully addressed by primary health care professionals.

\section{PRIMARY CARE AS OPPORTUNITY TO IMPLEMENT PROGRAMS FOR WEIGHT AND STIGMA CONTROL OF OBESE ADOLESCENTS IN THE COMMUNITY}

The percent of obese adolescents who maintain their obesity as adults is increasing. In the United States, federal statistics estimate that $80 \%$ of overweight adolescents grow up to be obese adults, leading to obesity-related health problems. Since pharmacotherapy options for treatment of adolescent obesity are very limited, developing a comprehensive management program focused on behavioral changes is the reasonable solution. Primary care practitioners address and positively influence many somatic problems that are consequences of obesity such as hypertension, dyslipidemia, insulin resistance, type 2 diabetes, sleepdisordered breathing [12-14]. In addition to the physical problems associated with obesity, considerable attention must be paid to stigma and discrimination against obese adolescents.

Family doctors develop an ongoing, personal patient-physician relationship, so it is important that they determine how obese adolescents relate to others, manage the stress and barriers they face [15], helping them to make healthy choices. Most families highly value the input of family doctors and welcome their involvement, which places them in a strong position to manage obese adolescents health and emotional problems $[2,16]$. Despite the fact that adolescent obesity have increased dramatically in recent decades, with $34 \%$ of adolescents currently overweight or obese [17], it has been understudied compared with adults and preadolescents obesity [18]. However, the teenage period is a favorable time to promote healthy lifestyle and to influence behaviors with risk for the physical, mental and social health of the future adults. Primary care settings provide opportunity for translating expert recommendations for healthy life optimisation from childhood, adolescence into adolhood $[19,20]$, as they have the staff to provide counseling and facilities, including through telemedicine, as virtual visits are more attractive and comfortable for obese adolescents [21].

Models for implementing expert recommendations for weight management interventions with adolescents and stigma control require development and testing [22], especially in primary care. Comprehensive lifestyle optimisation programs including diet, physical activity counseling and behavioral management training are efficacious, but they were rarely conducted in primary care settings [23].

There are several challenges which could be encountered during different phases of research regarding the lifestyle optimization of obese adolescent in primary care [18]. In the framework of the curricular reform of the family medicine residency program a study design in the community served by the family physician trainer and carried out with the family medicine residents involvement was included in the training of future family doctors.

Based on the experience of the authors in research activities in the field of healthy lifestyle promotion $[1,2,18,21,24-28]$, we proposed some study designes on the obese adolescents' health issues. We describe an integrative community-based educational program dedicated to the social and physical health consequences of adolescents' weight stigma that should be implemented in primary care. 
The design of the study to be implemented in primary care aims to increase the efficiency and sustainability of community-based educational programs and includes two components.

\section{The body weight control program}

It encompasses a set of principles and techniques for modifying diet and exercise, teaching adolescents how to achieve their eating and exercise goals by methods such as:

- setting goals: to reduce weight, improve diet by changing bad meal patterns, increase the amount of physical activity

- self-monitoring: keeping records (food diary) of skipping breakfast, food intake calories, portion sizes, sweetened beverage consumption; keeping records of physical activity and screen time (physical activity diary)

- weighing weekly: records of weight loss, stagnation or gain weight

- identifying barriers for goal achievement and solving problems through a tailored plan: avoiding snacking patterns in between meals, improving bad sleep patterns (late hours of sleep, nocturnal binge eating, short sleep duration)

- control of eating stimulus and binge eating prevention: modifying the food and physical activity environment to make healthful choices more available

- rewarding for reached goals provided by family medicine residents, nurses rather than family members

- promoting adolescent autonomy: telephone contact with adolescent and mail contact with parent.

\section{The weight stigma control}

- Social activities diary (social diary) will help to schedule social activities and record the number of missed opportunities to meet with colleagues for fear of being teased or bullied.

- The medical visits diary will record the number of appointments to the doctor avoided by moti- vations such as shame of the body's appearance and fear of anti-fat attitudes. Adapting the duration and quality of time invested by the family doctor to the complexity of the obese teenagers' problems facilitates the expression of their weight- based emotional problems and helps to identify new barriers to address.

- Focus groups with parents, teachers, school psychologists will include discussions on barriers, seeking help to manage the stigma of the obese child and concerns about being considered a poor parent. The primary care practitioners should emphasize the parents' role in the process.

By administering self-report questionnaires to both adolescents and parents, before and after educational programs, as well as at one year of follow-up, we will be able to test the effectiveness of this communitybased weight and stigma control educational program.

\section{CONCLUSIONS AND IMPLICATIONS FOR PRIMARY CARE PRACTICE}

Primary care practitioners are not confident enough in recognizing emotional problems of obese adolescents and have lack of training in this area. Given the time constraints experienced by family physicians, they often do not consider themselves able to manage the victimization of obese adolescents and prefer to work with other health professionals.

The increased prevalence of adolescents' obesity and the social and physical health consequences of weight-based stigmatization, require support in implementing weight and stigma control educational programs in primary care, access to evidence-based interventions and greater resources.

Psycho-educational skills development in the future family doctors training will lead to greater efficacy in addressing emotional needs of obese adolescents. Their increased involvement in counseling parents will help better cope with their children's eating disorders and weight-based victimization.

Conflict of interest: none declared Financial support: none declared

\section{REFERENCES}

1. Valea A, Silaghi C, Ghervan $\mathrm{H}$, et al. Morbid child obesity with possible RohhadnetRohhad syndrome. Acta Endocrinologica (Buc). 2014; 10(3):515-524.

2. Lotrean LM, Popa I, Florea M, et al. Actual Weight, Perceived Weight and Desired Weight of Romanian School Children by Parents and Children. Medicina. 2021;57:333
3. Fagot-Campagna A, Pettitt DJ, Engelgau MM, et al. Type 2 diabetes among North American children and adolescents: an epidemiologic review and a public health perspective. J Pediatr. 2000;136(5):664-672.

4. Willie SM, Wojciechowski B, Garvey T. Insulin resistance and defective glucoseinsulin coupling in ketosis-prone type 2 diabetes at African-American children. Diabetes. 1998;46:A306.

5. The NS, Suchindran C, North KE, et al. Association of adolescent obesity with risk of severe obesity in adulthood. JAMA. 2010;304(18):2042-2047.

6. Rundle AG, Factor-Litvak P, Suglia SF, et al.Tracking of Obesity in Childhood into Adulthood: Effects on Body Mass Index and 
Fat Mass Index at Age 50. Child Obes. 2020;16(3):226-233.

7. Puia IC, Stanculete MF, Puia A, et al. Patients' perception of weight-related stigma in a romanian sample. Journal of EvidenceBased Psychotherapies. 2017; 17(2):147-157.

8. Madowitz J, Knatz S, Maginot T, et al. Teasing, depression and unhealthy weight control behaviour in obese children. Pediatr Obes. 2012;7(6):446-452.

9. Phelan SM, Dovidio JF, Puhl RM, et al. Implicit and explicit weight bias in a national sample of 4,732 medical students: the medical student CHANGES study. Obesity. 2014;22(4):1201-1208.

10. Puhl RM, Heuer CA. The stigma of obesity: a review and update. Obesity. 2009;17(5):941-64.

11. Puhl R, Brownell KD. Ways of coping with obesity stigma: review and conceptual analysis. Eat Behav. 2003;4:53-78.

12. Lazea C, Asavoaie C, Al-Khzouz C, et al. Rare complications of neurofibromatosis 1 diagnosed incidentally in two children. Therapeutics and Clinical Risk Management. 2018;14:1547-1552.

13. Alexescu TG, Cozma A, Sitar-Tăut A, Negrean V, Handru MI, Motocu M, Tohănean $\mathrm{N}$, Lencu C, Para I. Cardiac Changes in Overweight and Obese Patients. Rom J Intern Med. 2016 Sep 1;54(3):161-172.

14. Lazea C, Sur L, Florea M. ROHHAD (Rapid-onset Obesity with Hypoventilation, Hypothalamic Dysfunction, Autonomic Dysregulation) Syndrome-What Every Pediatrician Should Know About the
Etiopathogenesis, Diagnosis and Treatment: A Review. Int J Gen Med. 2021;14:319-326.

15. O'Brien D, Harvey K, Howse J, et al. Barriers to managing child and adolescent mental health problems: a systematic review of primary care practitioners' perceptions. Br J Gen Pract. 2016;66(651):e693-e707.

16. Sayal K, Tischler V, Coope C, et al. Parental help-seeking in primary care for child and adolescent mental health concerns: qualitative study. $\mathrm{Br} J$ Psychiatry. 2010;197(6):476-481.

17. Ogden CL, Carroll MD, Curtin LR, et al. Prevalence of high body mass index in US children and adolescents, 2007-2008. JAMA. 2010;303(3):242-249.

18. Lotrean L, Popa M, Santillan EA, et al. Methodological challenges in research regarding the lifestyle of school children. Revista de Cercetare si Interventie Sociala 2014:44:321-331.

19. Lyznicki JM, Young DC, Riggs JA, et al. Obesity: assessment and management in primary care. Am Fam Physician. 2001;63(11):2185-2196.

20. Kubik MY, Story M, Davey C. Obesity prevention in schools: current role and future practice of school nurses. Prev Med. 2007;44(6):504-507.

21. Florea M, Lazea C, Gaga R, et al. Lights and shadows of the perception of the use of telemedicine by Romanian family doctors during the COVID-19 pandemic. Int J Gen Med. 2021;14:1576-1587.

22. Krebs NF, Jacobson MS. Prevention of pediatric overweight and obesity. Pediatrics. 2003;112(2):424-430.
23. Barlow SE. Expert committee recommendations regarding the prevention, assessment, and treatment of child and adolescent overweight and obesity: summary report. Pediatrics. 2007; 120(suppl 4):S164-S192.

24. Florea M,Ţalu Ş, Talu M. Patient simulation experience in family medicine residents' education. IFMBE Proceedings MEDITECH 2009 "International Conference on Advancements of Medicine and Health Care through Technology", Springer-Verlag GmbH Eds. Heidelberg, Germany. 2009;26:25-28.

25. Lotrean LM, Ursu D, Florea M, et al. Lifestyle and cardiovascular health: opinions and behaviors among adults having relatives with cardiovascular diseases. Health, Sports \& Rehabilitation Medicine 2020;21(1):4-8.

26. Lotrean LM, Florea M, Lencu C. Lifestyle and Cancer Prevention-Opinions and Behaviors Among Romanian University Students. Int J Gen Med. 2021; 14:1525-1532.

27. Lotrean LM, Man M, Gavrilescu C, et al. Electronic Cigarette Use and Its Relationship with Smoking and Alcohol and Illicit Drug Consumption among Romanian University Students. Medicina. 2021;57:137.

28. Lotrean LM, Ailoaiei R, Popa M, et al.The Use of Information Technology for Smoking Cessation: Opinions of Romanian Patients from General Practitioners. Revista de Cercetare si Interventie Sociala 2021; 73:312-325. 